\title{
OPTIMUM TARIFFS AND RETALIATION: \\ How Country Numbers MATTER
}

\section{by}

Francis Bloch and Ben Zissimos

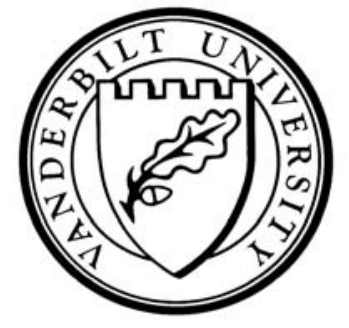

Working Paper No. 08-W02

January 2008

\section{DEPARTMENT OF ECONOMICS \\ VANDERBILT UNIVERSITY \\ NASHVILLE, TN 37235}

www.vanderbilt.edu/econ 


\title{
Optimum Tariffs and Retaliation: How Country Numbers Matter ${ }^{1}$
}

\author{
Francis Bloch \\ GREQAM and Ecole Superieure de Mecanique de Marseille \\ Ben Zissimos ${ }^{2}$ \\ Vanderbilt University
}

First Draft November 2007

\begin{abstract}
This paper presents a North-South model of international trade in which (i) there is a relatively small number of countries in the North and (ii) the North is relatively abundant in capital while the South is relatively abundant in labor. Using new methods in monotone comparative statics, the effect of changes in country numbers on the outcome of a "tariff war" is studied. It is shown that terms-of-trade and welfare in the North are greater the larger the number of countries in the South and vice versa. The paper also studies the relationship between the number of countries in the world market and its performance in terms of efficiency. It is shown that, as the world economy is replicated, the equilibrium in a tariff war converges monotonically towards the competitive equilibrium of free trade.

KEYwords. Comparative statics, efficiency, North-South, tariff war, terms of trade.

JeL Classification Numbers: F02, F13, F15, C73.
\end{abstract}

\footnotetext{
${ }^{1}$ We are grateful for comments from seminar participants at Drexel University, University of Oregon, Vanderbilt University, the GPED 50th Anniversary Conference, and the North American Summer Meetings of the Econometric Society at Duke University.

${ }^{2}$ Dept. of Economics, Vanderbilt University, Nashville, TN 37235.

Tel: ++16153223339 .

Fax: ++1 6153438495 .

E-mail: ben.zissimos@vanderbilt.edu
} 


\section{Introduction}

Ever since Johnson (1953-4) first raised the subject, scholars of international trade have been interested in the relationship between relative country size and the outcome of a tariff war. The reasons for this interest are easy to see. Study of this relationship raises interesting questions about how countries' strategic interactions depend on their relative output levels (Kennan and Riezman 1988) and also about how a country's power on the world market is determined by the underlying primitives (Syropoulos 2002). In addition, the question of country size is of considerable practical importance for understanding the outcome of actual tariff wars and trade negotiations (Whalley 1985). Perhaps no less important, for the same basic reasons, is the issue of how the numbers of countries with differing underlying factor endowments affect the outcome of a tariff war. Yet this issue has gone largely overlooked by scholars of international trade. The reason for this avoidance is equally easy to grasp. The issue is potentially intractable since, in an environment where countries differ, each country interacts strategically with a variable number of others.

The present paper shows that the question of how country numbers affect the outcome of a tariff war may be rendered tractable by introducing new methods in monotone comparative statics to the field of international trade. These methods have been developed to address questions of how the number of players affects the equilibrium outcome (Topkis 1998): how the number of firms in the market affects production levels under Cournot competition (Amir and Lambson 2000); how the number of traders affect the volume of trade in a strategic market game (Amir and Bloch forthcoming). This present paper introduces the methods to an international trade setting and shows how they can be used to yield new insights about the relationship between the distribution of countries

(and in turn their underlying factor endowments) across regions of the world economy and the outcome of a tariff war.

The model is placed in a familiar setting where trade takes place between the North and the South. The North is relatively abundant in capital and the South is relatively abundant in labor. This much is standard in Heckscher-Ohlin trade theory with protection. The novel feature of the model is that there may be any number of countries in the North and any number of countries in the South. All countries, whether in the North or in 
the South, produce the same (homogeneous) manufactured good and the same (homogeneous) primary product. But since all Northern countries have (identical) relatively large endowments of capital, and since manufactures use capital intensively, Northern countries export manufactures in equilibrium. Conversely, all Southern countries have (identical) relatively large endowments of labor, so they export primary products in equilibrium. ${ }^{3}$

The analysis of a tariff-game in the present paper follows Amir and Lambson's (2000) analysis of Cournot oligopoly and Amir and Bloch's (forthcoming) analysis of a marketgame. The tariff game between countries in one region is shown to be supermodular. To put this in terms more familiar from trade theory, tariffs between countries in one region are strategic complements; if one country lowers its tariff then it is a best response for all other countries in that region to lower their tariffs as well. Consequently, the comparative statics properties of the model are found to be monotone. Comparative statics can then be carried out at two levels. We will first examine the effects of a change in the number of countries in one region, holding constant the number of countries in the other region. Combining the analysis of each separate region, we will then consider the effects of a simultaneous increase in the number of countries in both regions that holds them in the same proportion. This we will refer to as a replication of the world economy. ${ }^{4}$

The simple basic insight we will obtain from this framework is that Southern countries get relatively poor terms-of-trade on the world market because there is a relatively large number of them and so they compete more aggressively with each other to put primary products onto the world market. It is important to emphasize that the aggressiveness of

\footnotetext{
${ }^{3}$ Most of the literature on tariff wars follows Johnson (1953) in using models of just two countries. For example, Gorman (1958) shows that Johnson's model generalizes because Johnson's preference structure is a special case of the Gorman polar form. Tower (1975) analyzes a trade war under alternative strategic instruments (quotas) and adjustment processes. In a general setting, Otani (1980) establishes general conditions for existence of Nash equilibrium in a tariff war. As mentioned above, Kennan and Riezman (1987) and Syropoulos (2002) investigate the role of country size in the determination of optimal tariffs. Optimal tariffs have been studied in models of many countries using numerical simulations; see Hamilton and Whalley (1983) for an initial contribution. The idea of strategic tariff setting has been integrated into the literature on preferential trade agreements, which also involves models of more than two (usually three) countries. But these literatures do not study the relationship between country numbers and optimal tariffs. Free trade agreements and preferential trade agreements present interesting possibilities that will be investigated using the present framework in future.

${ }^{4}$ The idea behind increasing the number of countries is to understand how the structure of the economy affects efficiency and equity. It is not intended to consider the question of how, say, trade between World Trade Organization (WTO) members is affected by the introduction of new members, although the framework of this paper could be developed in that direction.
} 
competition is determined not by firms (who behave competitively) but by governments through strategic tariff setting. Obviously, these insights could not be obtained in the conventional model of a tariff war in which there are just two countries.

The insights gained from analyzing replication are more abstract. We will show that, as the world economy is replicated, the tariff war equilibrium converges monotonically to the perfectly competitive equilibrium (the efficient outcome of free trade). This provides a nice interface between the early international trade literature based on perfect competition and the newer literature based on strategic interaction between countries.

Finally, combining the previous two results, the model can be used to provide a new perspective on the equity implications of international trade. In particular, an example presented at the end of the paper shows that the more scarce is the good that a country exports in equilibrium, the worse off the country becomes when the world economy is replicated. This surprising result occurs because although a country gains from the increase in competition to supply it with exports from the other region, at the same time its own export becomes less scarce on world markets and the overall effect of replication is to undermine its power on world markets.

The paper also makes a broader contribution. The way we have characterized the world economy appears to have the potential to shed light on the aggressiveness of competition amongst a particular group of countries versus another group of countries. Our framework in turn opens the door to an examination of coalition formation in trade talks; in particular the bargaining which has taken place in the Doha Round between the long standing Quad and the more recently formed G20. ${ }^{5}$

The paper proceeds as follows. In the next section, we will set up the basic model. We will then analyze the properties of this model in Section 3, laying the foundations we will need to characterize equilibrium in Section 4 and carry out comparative statics. An example is presented in Section 5. Conclusions are drawn in Section 6.

\footnotetext{
${ }^{5}$ The Quad consists of Canada, the EU, Japan, and the US. The G20 is a group of developing countries which includes Brazil and India. Jawara and Kwa (2003) argue that the trade negotiations at Doha centered mainly around these two country groups.
} 


\section{A North-South Model with Many Countries}

We will extend a standard general model of international trade. In the standard model there are two countries, each of which produces two goods using two factors. The two goods, manufactures and primary products, are intensive in capital and labor respectively. Our model is identical except that there are more than two countries. The set of all countries $N$ is divided into two sets: The North, denoted by $A$, consists of the set of countries $A=\{1,2, \ldots, a, \ldots, x\}$; the South, denoted by $B$, consists of the set of countries $B=\{x+1, x+2, \ldots, b, \ldots, x+y\}$. There are $x$ countries in the North and $y$ countries in the South. Following notation from the matching literature, $a$ will be the representative Northern country and $b$ will be the representative Southern country. Where convenient, we will use $i$ to refer to any country in $N$. Manufactures will be denoted good 1 and primary products good 2. Unless otherwise stated, a country will be denoted by a superscript and a good will be denoted by a subscript. Country $i$ has an inelastically supplied vector of factor inputs $\mathbf{v}^{i}=\left\{k^{i}, l^{i}\right\}$. Northern countries have a relatively large endowment of capital. The endowment of capital and labor for all countries in the North is identical and may be represented by $\mathbf{v}^{a}=\left\{k^{a}, l^{a}\right\}$. Analogously, the identical endowment of all countries in the South may be represented by $\mathbf{v}^{b}=\left\{k^{b}, l^{b}\right\}$. All countries are of identical size in the sense that $k^{i}+l^{i}=1$ for all $i \in N$.

\subsection{A Single Country}

In this section we will define a tariff distorted equilibrium for country $i$, taking tariffs and world prices as given. Each country has a population of atomistic citizens whose mass is normalized to unity; citizens behave as price-takers in their dual roles as consumers and producers.

Technologies exhibit constant returns to scale and are identical across all countries. All markets are perfectly competitive and there are no domestic distortions. The utility function is strictly quasi-concave in goods 1 and 2 respectively. Tastes are identical and homothetic. So we can formulate the analysis in per-capita terms without loss of generality. Consequently, we can fix the utility level at $\mu^{i}$ and solve for the minimum

level of expenditure required to meet that level. In addition, let $p_{j}^{i}$ be the domestic price 
of good $j$ and country $i, i \in\{1,2\}$. The we can denote with $E^{i}\left(p_{1}^{i}, p_{2}^{i}, \mu^{i}\right)$ and $R^{i}\left(p_{1}^{i}, p_{2}^{i}, \mathbf{v}^{i}\right)$ country $i$ 's expenditure and revenue functions respectively. Both functions are assumed to be twice continuously differentiable in their arguments. The compensated (Hicksian) demand function for good $j$ is $c_{j}^{i}=E_{p_{j}}^{i}\left(=\partial E^{i} / \partial p_{j}^{i}\right)$, where $\partial c_{j}^{i} / \partial p_{j}^{i}=E_{p_{j} p_{j}}^{i} \leq 0$ by the concavity of the expenditure function in prices. The supply function for good $j$ may be defined from the revenue function analogously. ${ }^{6}$

Let $p^{i}$ be the domestic relative price of country $i$ 's importable measured in terms of its exportable and let $q^{i}$ be the world price of the same good. Let $\tau^{i}$ be country $i$ 's ad valorem import tariff and assume that this is the only available policy instrument. Then we can express the relationship between domestic and world relative prices for country $i$ as $^{7}$

$$
p^{i}=\left(1+\tau^{i}\right) q^{i}, i \in A, B
$$

Let $m^{i}$ denote country $i$ 's imports. We may then write:

$$
m^{i}=E_{p}^{i}-R_{p}^{i}, i \in A, B
$$

This defines country $i$ 's average import demand function in terms of excess demand. In addition, the budget constraint for country $i$ is as follows:

$$
E^{i}\left(p^{i}, \mu^{i}\right)=R^{i}\left(p^{i}, \mathbf{v}^{i}\right)+\tau^{i} q^{i} m^{i}, i \in A, B
$$

Each country's average expenditure is equal to its average income, which is derived from output plus tariff revenue. Taking $\tau^{i}$ and $q^{i}$ as given, a (tariff distorted) competitive equilibrium is established in the domestic economy using equations (2.1)-(2.3).

\subsection{The World Market}

We will now define equilibrium in the world market in terms of a symmetric general tariff game; the tariff game played by all countries. We begin by introducing some notation. The vector of all tariffs, $\boldsymbol{\tau}=\left(\tau^{1}, \ldots, \tau^{a}, \ldots, \tau^{x}, \tau^{x+1}, \ldots, \tau^{b}, \ldots, \tau^{x+y}\right)$, can be partitioned into tariffs set by Northern countries, denoted by $\boldsymbol{\tau}^{a}$, and tariffs set by Southern countries, denoted by $\boldsymbol{\tau}^{b} ; \boldsymbol{\tau}^{a}=\left(\tau^{1}, \ldots, \tau^{a}, \ldots, \tau^{x}\right)$ and $\boldsymbol{\tau}^{b}=\left(\tau^{x+1}, \ldots, \tau^{b}, \ldots, \tau^{x+y}\right)$ respectively. It will

\footnotetext{
${ }^{6}$ See Dixit and Norman (1980) for further details.

${ }^{7}$ Country $i$ makes no intervention in the market for the good that it exports, so $p_{j}^{i}=q_{j}$ for that good.
} 
also be helpful to have notation for tariffs set by all countries in $A$ except country $a$, which we will denote by $\boldsymbol{\tau}^{-a}$, and tariffs set by all countries in $B$ except country $b$, denoted by $\tau^{-b}$.

The extensive form of the general (symmetric) tariff game is as follows. First, each country $i$ (simultaneously and without communicating - this is the sense in which the game is symmetric) chooses its import tariff $\tau^{i}$. Then, given world prices $\mathbf{q}=\left\{q_{1}, q_{2}\right\}$ and tariffs, perfect competition in production takes place. Next, the representative consumer in each country chooses consumption to maximize budget constraints. This yields the usual indirect utility functions and excess demands. Then, conditional on tariffs, $\boldsymbol{\tau}$, markets clear and world prices $\mathbf{q}$ are determined. ${ }^{8}$ These world prices will of course depend on tariffs, i.e. $\mathbf{q}=\mathbf{q}(\boldsymbol{\tau})$, as will tariff revenues. If equilibrium prices are unique, given tariffs, then the mapping $\mathbf{q}($.$) is one-to-one. Then the indirect utility function for$ country $i$, which we will denote with $u^{i}(\cdot)$, can be written as a function only of tariffs; $u^{i}\left(\mathbf{q}(\boldsymbol{\tau}), \tau^{i}\right){ }^{9}$

World prices are determined in the usual way through the world market clearing condition. By the Heckscher-Ohlin theorem, and our assumptions which conform to a Heckscher-Ohlin framework, we know that the countries in $A$ will import good 2 in freetrade equilibrium while the countries in $B$ will import good 1. It follows that the same pattern of trade will be maintained if at least one country from each region sets nonprohibitive tariffs. ${ }^{10}$ Consequently, we have the following simple expressions for aggregate value of imports to each region: $q_{2} M^{A}=\sum_{i \in A} q_{2} m^{i} ; q_{1} M^{B}=\sum_{i \in B} q_{1} m^{i}$. Let good 1 be the numeraire, $q_{1}=1$, and let $q_{2}=q$. Then we may write the world market clearing condition as follows:

$$
q M^{A}=M^{B}
$$

Given that the import demand function for each element $m^{i}$ is continuous in $q^{i}$ and

${ }^{8}$ As this is a general equilibrium model, prices are determined only up to a scalar, and so some normalization (e.g. choice of numeraire) must be made. This technical detail and others are dealt with below.

${ }^{9}$ Transfers are not allowed between countries. This is deemed to be a reasonable assumption in the trade literature, since although transfers do happen they are often constrained by extraneous factors.

${ }^{10}$ Perverse patterns of trade may be possible under extreme tariff settings where some countries subsidize imports. While such possibilities may be interesting, they will not have a bearing on the symmetric equilibrium we consider so we will rule them out. 
$\tau^{i}$, the world market clearing condition implicitly defines a mapping from the vector of tariffs to the vector of world prices.

\subsection{Equilibrium and Efficiency}

In a trading equilibrium,

$$
M^{A}>0 \text { and } M^{B}>0 .
$$

If the equilibrium is not a trading equilibrium then it is autarkic.

We can now define a trading equilibrium in tariffs as a vector of tariffs

$$
\overline{\boldsymbol{\tau}}=\left(\bar{\tau}^{1}, \ldots, \bar{\tau}^{x}, \bar{\tau}^{x+1}, \ldots, \bar{\tau}^{x+y}\right)
$$

such that

(i) for any country $a \in A, \bar{\tau}^{a}$ maximizes $u^{a}\left(\mathbf{q}\left(\tau^{a}, \overline{\boldsymbol{\tau}}^{-a}, \overline{\boldsymbol{\tau}}^{b}\right), \tau^{a}\right)$;

(ii) for any country $b \in B, \bar{\tau}^{b}$ maximizes $u^{b}\left(\mathbf{q}\left(\tau^{b}, \overline{\boldsymbol{\tau}}^{-b}, \overline{\boldsymbol{\tau}}^{a}\right), \tau^{b}\right)$.

Standard arguments can be used to prove existence of an equilibrium, which is just a Nash equilibrium of the tariff game.

Following standard definitions, world welfare is the sum of all national welfares, and world efficiency is given by

$$
\max _{\boldsymbol{\tau}} \sum_{a \in A} u^{a}\left(\mathbf{q}(\boldsymbol{\tau}), \tau^{a}\right)+\sum_{b \in B} u^{b}\left(\mathbf{q}(\boldsymbol{\tau}), \tau^{b}\right) .
$$

Since there are no domestic distortions in the model, world efficiency corresponds to world free trade.

\section{Analysis of the Model}

Our ultimate aim is to characterize the reaction functions of the representative countries, $a$ and $b$, and then analyze how each reaction function is affected by a change in $x$ and $y$. In this section we prepare the ground by examining the economic properties of the model, from which we will be able to define concretely the payoffs to the general tariff game. 


\subsection{A Single Country}

Analysis of the single country model follows Syropoulos (2002). First, we need some notation. Country $i$ 's expenditure share on its importable may be written as $\sigma_{c}^{i} \equiv p^{i} E_{p}^{i} / E^{i}$ and the share of revenue contributed by production of good $j$ as $\sigma_{s}^{i} \equiv p^{i} R_{p}^{i} / R^{i}$. Also, let $T^{i} \equiv \tau^{i} /\left(1+\tau^{i}\right)$. Then, from equations (2.1)-(2.3), the equilibrium solution for $m^{i}$ is as follows:

$$
m^{i}=m^{i}\left(p^{i}, T^{i}, \mathbf{v}^{i}\right)=\frac{R^{i}\left(\sigma_{c}^{i}-\sigma_{s}^{i}\right)}{p^{i}\left(1-T^{i} \sigma_{c}^{i}\right)}, i \in A, B,
$$

where $T^{i} \in[0,1)$. Since $1-T^{i} \sigma_{c}^{i}>0$, (3.1) implies that, as long as revenue and domestic relative prices are finite, if $\sigma_{c}^{i}-\sigma_{s}^{i}>0$ then $m^{i}>0$. In words, to import good $j$ country $i$ 's expenditure share on good $j$ must exceed its revenue share.

The solution for country i's indirect utility function is as follows:

$$
u^{i}=u^{i}\left(p^{i}, T^{i}, \mathbf{v}^{i}\right)=\frac{R^{i}\left(1-T^{i} \sigma_{s}^{i}\right)}{E^{i}\left(1-T^{i} \sigma_{c}^{i}\right)}, i \in A, B .
$$

In (3.2), diversification of production requires that $0<1-T^{i} \sigma_{s}^{i} \leq 1$.

We can now undertake comparative statics on imports in order to characterize their response to a change in tariffs and the terms of trade. First, using (2.1), let us rewrite (3.1) as a function of the terms-of-trade and tariffs. To do so, we will adopt the convention of "hat algebra" that a "^" over a variable denotes a percentage change. Also, let $q^{a}=q$ and $q^{b}=1 / q$ represent the terms-of-trade of countries $a$ and $b$ in the world market. Then we may express the direct price elasticity of import demand as $\varepsilon^{i} \equiv-\hat{m}^{i} / \hat{q}^{i}(>0)$. Also, let $\phi^{i} \equiv-\left(1+\tau^{i}\right) \hat{m}^{i} / \partial \tau^{i}(>0)$; the variable $\phi^{i}$ captures the absolute value of the combined production and substitution elasticities in response to a change in tariffs. By definition, $\hat{q} \equiv \hat{q}^{a}=-\hat{q}^{b}$. We can then write the total derivative of (3.1) for countries $a$ and $b$ respectively as follows:

$$
\begin{aligned}
& \hat{m}^{a}=-\varepsilon^{a} \hat{q}-\phi^{a} \frac{d \tau^{a}}{1+\tau^{a}} \\
& \hat{m}^{b}=\varepsilon^{b} \hat{q}-\phi^{b} \frac{d \tau^{b}}{1+\tau^{b}} .
\end{aligned}
$$

These expressions capture, for the representative Northern and Southern country respectively, the direct and indirect (i.e. terms-of-trade) effects of a tariff change on imports. 


\subsection{Tariffs and the Terms-of-Trade}

We can now ascertain how the terms-of-trade are determined. Denote by $s^{i}$ the share of total imports to its region received by country $i$; This share is given by $s^{i}=m^{i} / M^{I}$, where if $i \in A$ then $I=A$ and if $i \in B$ then $I=B$. Totally differentiating the world market clearing condition, (2.4), we obtain

$$
\begin{aligned}
& \hat{q}+s^{1} \hat{m}^{1}+\ldots+s^{a} \hat{m}^{a}+\ldots+s^{x} \hat{m}^{x} \\
= & s^{x+1} \hat{m}^{x+1}+\ldots+s^{b} \hat{m}^{b}+\ldots+s^{x+y} \hat{m}^{x+y} .
\end{aligned}
$$

Using (3.3) and (3.4) in (3.5), and rearranging, we obtain

$$
\begin{aligned}
\hat{q}= & s^{x+1} \frac{\phi^{x+1}}{\Delta} \frac{d \tau^{x+1}}{1+\tau^{x+1}}+\ldots+s^{b} \frac{\phi^{b}}{\Delta} \frac{d \tau^{b}}{1+\tau^{b}}+\ldots+s^{x+y} \frac{\phi^{x+y}}{\Delta} \frac{d \tau^{x+y}}{1+\tau^{x+y}} \\
& -s^{1} \frac{\phi^{1}}{\Delta} \frac{d \tau^{1}}{1+\tau^{1}}-\ldots-s^{a} \frac{\phi^{a}}{\Delta} \frac{d \tau^{a}}{1+\tau^{a}}-\ldots-s^{x} \frac{\phi^{x}}{\Delta} \frac{d \tau^{x}}{1+\tau^{x}}
\end{aligned}
$$

where $\Delta \equiv\left(s^{1} \varepsilon^{1}+\ldots+s^{a} \varepsilon^{a}+\ldots+s^{x} \varepsilon^{x}+s^{x+1} \varepsilon^{x+1}+\ldots+s^{b} \varepsilon^{b}+\ldots+s^{x+y} \varepsilon^{x+y}-1\right)$. We assume that $\Delta>0$; the Marshall-Lerner condition for world market stability holds. Equation (3.6) is obviously not a closed form solution for $\hat{q}$ since all $s^{i}$ depend on $q^{i}$. But since all right-hand-side variables are continuous in all their arguments, we can use this expression to evaluate the impact of a change in $\tau^{i}$ on $\hat{q}$. The implicit function theorem can be used to establish the familiar property that an increase in a country's tariff rate causes its terms-of-trade to improve.

We can also work out the impact of tariffs on domestic relative prices. Using (2.1) to determine $p^{i}$ and then differentiating with respect to tariffs and substituting for $\hat{q}$ using (3.6) yields

$$
\begin{aligned}
& \hat{p}^{a}=\left(1-s^{a} \frac{\phi^{a}}{\Delta}\right) \frac{d \tau^{a}}{1+\tau^{a}}-\sum_{i \in A \backslash a} s^{i} \frac{\phi^{i}}{\Delta} \frac{d \tau^{i}}{1+\tau^{i}}+\sum_{i \in B} s^{i} \frac{\phi^{i}}{\Delta} \frac{d \tau^{i}}{1+\tau^{i}} \\
& \hat{p}^{b}=\left(1-s^{b} \frac{\phi^{b}}{\Delta}\right) \frac{d \tau^{b}}{1+\tau^{b}}-\sum_{i \in B \backslash b} s^{i} \frac{\phi^{i}}{\Delta} \frac{d \tau^{i}}{1+\tau^{i}}+\sum_{i \in A} s^{i} \frac{\phi^{i}}{\Delta} \frac{d \tau^{i}}{1+\tau^{i}} .
\end{aligned}
$$

From these equations we see that, in the absence of Meltzer's tariff paradox, $\hat{p}^{a}$ depends positively on $\tau^{a}$ and $\tau^{i}, i \in B$, but negatively on $\tau^{i}, i \in A \backslash a$. The effect of $\tau^{a}$ on $\hat{p}^{a}$ operates directly through (2.1). The effect of $\tau^{i}, i \in B$, operates by bringing about an increase in $\hat{q}$; see (3.6). The effect of $\tau^{i}$ for $i \in A \backslash a$ operates by reducing $\hat{q}$; again see (3.6). The effects of tariffs on $\hat{p}^{b}$ are analogous. 


\subsection{Tariffs and Welfare}

We are now able to analyze the effects of tariff changes on welfare. By totally differentiating (2.3) for countries $a$ and $b$ respectively, we obtain

$$
\begin{aligned}
& E_{\mu^{a}}^{a} d \mu^{a}=q^{a} m^{a}\left(-\hat{q}+\tau^{a} \hat{m}^{a}\right) \\
& E_{\mu^{b}}^{b} d \mu^{b}=q^{b} m^{b}\left(\hat{q}+\tau^{b} \hat{m}^{b}\right) .
\end{aligned}
$$

The two terms in brackets capture the terms-of-trade and volume-of-trade effects on welfare respectively.

Working with (3.3) and (3.4), $\hat{m}^{a}$ and $\hat{m}^{b}$ can be expressed in terms of domestic and world prices. First note that the compensated price elasticity of import demand takes the form

$$
\eta^{i}=-\left(p^{i} E_{p p}^{i}-p^{i} R_{p p}^{i}\right) /\left(E_{p}^{i}-R_{p}^{i}\right)>0
$$

Using $\eta^{i}$, we may then write

$$
\begin{aligned}
& \hat{m}^{a}=-\frac{\eta^{a}}{1-T^{a} \sigma_{c}^{a}} \hat{p}^{a}-\frac{\sigma_{c}^{a} /\left(1+\tau^{a}\right)}{1-T^{a} \sigma_{c}^{a}} \hat{q} \\
& \hat{m}^{b}=-\frac{\eta^{b}}{1-T^{b} \sigma_{c}^{b}} \hat{p}^{b}+\frac{\sigma_{c}^{b} /\left(1+\tau^{b}\right)}{1-T^{b} \sigma_{c}^{b}} \hat{q} .
\end{aligned}
$$

The first term on the right hand side measures the effect of a change in domestic prices on imports through substitution of goods in consumption and production. The second term is a terms-of-trade-cum-income effect. If a country's terms-of-trade improve then that country imports more from the other region due to the fact that its income has risen and both goods are normal.

Substituting the respective equations for $\hat{m}^{a}$ and $\hat{m}^{b}$ from (3.10) into (3.9), we can rewrite $(3.9)$ as

$$
\begin{aligned}
E_{\mu^{a}}^{a} d \mu^{a} & =\frac{q^{a} m^{a}}{1-T^{a} \sigma_{c}^{a}}\left(-\hat{q}-\tau^{a} \eta^{a} p^{a}\right) ; \\
E_{\mu^{b}}^{b} d \mu^{b} & =\frac{q^{b} m^{b}}{1-T^{b} \sigma_{c}^{b}}\left(\hat{q}-\tau^{b} \eta^{b} p^{b}\right) .
\end{aligned}
$$

By substituting (3.6) and (3.7) into the first equation in (3.11), we can derive a decom- 
position of welfare for country $a$ in terms of tariffs across all countries:

$$
\begin{aligned}
E_{\mu^{a}}^{a} d \mu^{a}= & \frac{q^{a} m^{a}}{1-T^{a} \sigma_{c}^{a}}\left[\left(s^{a} \frac{\phi^{a}}{\Delta}-\tau^{a} \eta^{a}\left(1-s^{a} \frac{\phi^{a}}{\Delta}\right)\right) \frac{d \tau^{a}}{1+\tau^{a}}\right. \\
& \left.+\sum_{i \in A \backslash a}\left(1+\tau^{i} \eta^{i}\right)\left(s^{i} \frac{\phi^{i}}{\Delta}\right) \frac{d \tau^{i}}{1+\tau^{i}}-\sum_{i \in B}\left(1+\tau^{i} \eta^{i}\right)\left(s^{i} \frac{\phi^{i}}{\Delta}\right) \frac{d \tau^{i}}{1+\tau^{i}}\right] .
\end{aligned}
$$

Analogously for country $b$,

$$
\begin{aligned}
E_{\mu^{b}}^{b} d \mu^{b}= & \frac{q^{b} m^{b}}{1-T^{b} \sigma_{c}^{b}}\left[\left(s^{b} \frac{\phi^{b}}{\Delta}-\tau^{b} \eta^{b}\left(1-s^{b} \frac{\phi^{b}}{\Delta}\right)\right) \frac{d \tau^{b}}{1+\tau^{b}}\right. \\
& \left.+\sum_{i \in B \backslash b}\left(1+\tau^{i} \eta^{i}\right)\left(s^{i} \frac{\phi^{i}}{\Delta}\right) \frac{d \tau^{i}}{1+\tau^{i}}-\sum_{i \in A}\left(1+\tau^{i} \eta^{i}\right)\left(s^{i} \frac{\phi^{i}}{\Delta}\right) \frac{d \tau^{i}}{1+\tau^{i}}\right] .
\end{aligned}
$$

Consider the effect of an increase in $\tau^{i}, i \in B \backslash b$ on $E_{\mu^{a}}^{a} d \mu^{a}$ and $E_{\mu^{b}}^{b} d \mu^{b}$. We see that, by

shifting the terms of trade in favor of the countries in $B$ this would reduce the welfare of country $a$ but increase the welfare of country $b$; see the second term on the second line of (3.12) and the first term on the second line of (3.13) respectively.

We can also use (3.12) and (3.13) to analyze the tariff problems of countries $a$ and $b$; in other words, we are now able to characterize the tariff game played in our 'North-South model with many countries'.

\section{Characterization of Equilibrium}

In principle, the tariff game described here is quite complex since many countries play strategies against one another simultaneously. Following Amir and Bloch (2004), which builds in turn on Amir and Lambson (2000), we can simplify the problem by characterizing the tariff game played between countries in one region, taking as given the tariffs of countries in the other region. After having shown a simple characterization of this game, it will then be straight-forward to characterize the equilibrium of the tariff game between countries in both regions.

\subsection{Characterization of Equilibrium for The Tariff Game of the North}

In the symmetric Cournot oligopoly analyzed by Amir and Lambson, the optimal quantity choice of an oligopolist only depends on the total output of the $(n-1)$ remaining firms. 
Amir and Bloch extend this approach to a market-game setting in which there are two sides to the market, where a 'side of the market' in their model is similar to a region in ours. They show that the optimal quantity placed on the market by a player on one side of the market depends on the quantity choices of the other $(n-1)$ players on the same side of the market, taking as given the quantity choices of players on the other side of the market. In this section we will show that the same approach as taken by Amir and Bloch can be extended to the present setting of a tariff game. The key difference is that quantities traded by one region can change through changes in the terms-of-trade even if strategies (here tariffs) of players (here countries) in that region do not change. ${ }^{11}$

Following Amir and Bloch (forthcoming), the procedure we will use to characterize equilibrium in the general tariff game is as follows. For given parameters, $x$ and $y$, characterize equilibrium of the (symmetric) tariff game of the North, $\Gamma\left(\tau^{b}\right)$, taking as given the tariff vector $\boldsymbol{\tau}^{b}$ of countries in the South (where $\boldsymbol{\tau}^{b}$ is fixed arbitrarily). In this way, obtain an equilibrium tariff vector $\overline{\boldsymbol{\tau}}^{a}$. Then characterize equilibrium for the (symmetric) tariff game of the South, $\Gamma\left(\boldsymbol{\tau}^{a}\right)$, to obtain the equilibrium tariff vector, $\overline{\boldsymbol{\tau}}^{b}$, taking as given the tariff vector $\boldsymbol{\tau}^{a}$. Since $\boldsymbol{\tau}^{a}$ is arbitrarily chosen, we may use the equilibrium tariff vector $\overline{\boldsymbol{\tau}}^{a}$ when obtaining $\overline{\boldsymbol{\tau}}^{b}$. In that case, $\overline{\boldsymbol{\tau}}^{b}$ must be a best-response to $\overline{\boldsymbol{\tau}}^{a}$. Finally, check that $\overline{\boldsymbol{\tau}}^{a}$ is a best response to $\overline{\boldsymbol{\tau}}^{b}$. If so, $\left(\overline{\boldsymbol{\tau}}^{a}, \overline{\boldsymbol{\tau}}^{b}\right)$ are a pair of mutual best response tariff vectors and, by the usual definition, we have characterized a Nash equilibrium.

We will restrict attention to proving existence and uniqueness of a symmetric equilibrium of the general tariff game; an equilibrium in which all countries in the North set the same unique equilibrium tariff, $\bar{\tau}^{a}$, and all countries in the South set the same unique equilibrium tariff, $\bar{\tau}^{b}$ (where in general $\bar{\tau}^{a} \neq \bar{\tau}^{b}$ ). ${ }^{12}$ To characterize this equilibrium, we follow the same procedure as above but, in the tariff game of the North, $\Gamma\left(\boldsymbol{\tau}^{b}\right)$, instead of allowing all tariffs in the vector $\tau^{b}$ to be set at different levels we assume that all countries in the South set the same tariff, $\tau^{b}$. In this case, the tariff game of the North is denoted

\footnotetext{
${ }^{11}$ In a market game quantities are chosen by players (traders) directly as their strategies; here players (governments) choose tariffs and have only an indirect influence over quantities traded, which are determined (subject to tariffs) through competitive interaction between producers and consumers. Remember that this process was described in Section 2.2 as part of the extensive form of the tariff game.

${ }^{12}$ There may exist interesting asymmetric equilibria of this game but we will not study them in the present paper.
} 
$\Gamma\left(\tau^{b}\right)$. The aim is then to prove existence and uniqueness of an equilibrium in which Northern governments all set a unique tariff at the same level $\bar{\tau}^{a}$. We then characterize the symmetric equilibrium of the tariff game of the South, $\Gamma\left(\tau^{a}\right)$, using $\bar{\tau}^{a}$. Thus we obtain $\bar{\tau}^{b}$ that is a best response to $\bar{\tau}^{a}$. If we are able to show that $\left(\bar{\tau}^{a}, \bar{\tau}^{b}\right)$ are a pair of mutual best responses then we have characterized a symmetric Nash equilibrium of the general tariff game. ${ }^{13}$

We now introduce the following assumption, which is imposed as a standing assumption throughout the analysis:

A1. $\varepsilon^{i}=\varepsilon>0$ for all $i \in A, B$.

A1 implies constant price elasticity of demand for imports; $\varepsilon$ does not change in response to a change in $p^{i}$. This is a restrictive assumption but it is useful in the present context. First, it is a sufficient condition which allows the model to be analyzed for any number of countries in each region, not just in a static setting but in comparative statics as well. Second, and just as importantly, it closes down the channels through which size affects best-response tariffs and facilitates focus on trade flows between regions and the effect that this has on the outcome of the general tariff game. ${ }^{14}$

We will now characterize the symmetric equilibrium of the general tariff game, starting with our characterization of equilibrium for the game $\Gamma\left(\tau^{b}\right)$. First let us solve for country a's best-response tariff, $\tilde{\tau}^{a}\left(\boldsymbol{\tau}^{-a}, \tau^{b}\right)$, which is obtained in the usual way by setting the first term inside the square brackets of (3.12) equal to zero and solving for $\tau^{a}$. (This is equivalent to calculating $d u^{a} / d \tau^{a}$, then setting the result equal to zero and solving for $\tau^{a}$.)

\footnotetext{
${ }^{13}$ Note that there is no further loss of generality, beyond that fact that we restrict attention to a symmetric equilibrium, in the assumption that all countries in the South set the same tariff $\tau^{b}$ in $\Gamma\left(\tau^{b}\right)$. The reason is that $\tau^{b}$ is introduced after the first order condition of government $a$ 's objective function is found.

${ }^{14}$ Assumption A1 is satisfied by Cobb-Douglas preferences. In his comprehensive analysis of the effect of country size on the outcome of a (two-country) tariff war, Syropoulos (2002) assumes that $\frac{p^{i}}{\varepsilon^{i}} \frac{\partial \varepsilon^{i}}{\partial p^{i}}>0$.
} 
We can now state our first result, which characterizes the best-response tariff function for country $a$ :

Proposition 1. In the game $\Gamma\left(\tau^{b}\right)$, the best-response tariff function for country $a$, $\tilde{\tau}^{a}\left(\boldsymbol{\tau}^{-a}, \tau^{b}\right)$, is the solution to the equation

$$
\tau^{a}=\frac{s^{a}}{\sum_{i \in A \backslash a} s^{i} \varepsilon+\sum_{i \in B} s^{i} \varepsilon-1} .
$$

We can see by inspection that Proposition 1 generalizes the solution for the bestresponse tariffs in a setting where there are just two countries with one in each region. In that case, $s^{a}=1$ and all other $s^{i}=0$ for $i \in A \backslash a, s^{b}=1$ and all other $s^{i}=0$ for $i \in B \backslash b$. Then we would obtain the familiar expression for the best-response tariff $\tilde{\tau}^{a}\left(\tau^{b}\right)=1 /\left(\varepsilon^{b}-1\right)$. Notice that our general characterization defines the best-response tariff not just as a function of $\tau^{b}$ but of $\boldsymbol{\tau}^{-a}$ (and $\boldsymbol{\tau}^{-b}$ ) as well.

In the next step towards the characterization of equilibrium in the tariff game of the North, let us examine the best response of $\tau^{a}$ to $\tau^{-a}$.

Lemma 1. In the game $\Gamma\left(\tau^{b}\right), \tau^{a}$ is an increasing function of $\boldsymbol{\tau}^{-a}$.

If a tariff in the vector $\boldsymbol{\tau}^{-a}$ is lowered then this results in a fall in import share of good 2 to country $a$ and a corresponding loss of welfare. In order to recover the loss of welfare, country a must lower its tariff. It follows that, for countries $1, \ldots, a, \ldots, x$ in the set $A$, tariffs are strategic complements; equivalently, the tariff game $\Gamma\left(\tau^{b}\right)$ is said to be supermodular.

Of course, both the initial reduction in $\tau^{-a}$ and the subsequent lowering of $\tau^{a}$ have the effect of reducing country $a$ 's terms-of-trade and hence income. In principle the income effect on the elasticity of demand for imports may be large enough to cause $a$ to try to offset the loss in terms-of-trade and hence income by increasing its tariff. The fact that we have fixed $\varepsilon^{i}$ at $\varepsilon$ prevents this possibility. 
The next result shows that if the $\Gamma\left(\tau^{b}\right)$ game is supermodular then the Nash equilibria of the tariff game of the North are symmetric.

Proposition 2. For any number of countries in the North, $x$, all Nash equilibria of the game $\Gamma\left(\tau^{b}\right)$ are symmetric.

Proof of Proposition 2. Suppose that we have an equilibrium in which, w.o.l.o.g., countries $1,2 \in A$ set tariffs $\bar{\tau}^{1}$ and $\bar{\tau}^{2}$ in such a way that $\bar{\tau}^{2}>\bar{\tau}^{1}$ and the tariffs of all other countries in $A$ are fixed at some (equal) level $\bar{\tau}^{a} \in \mathbb{R}_{+}$and all countries in $B$ are fixed at some (equal) level $\tau^{b} \in \mathbb{R}_{+}$. By Lemma 1 , we have that $\bar{\tau}^{1}$ is a strictly increasing function of $\bar{\tau}^{2}$ and also that $\bar{\tau}^{2}$ is a strictly increasing function of $\bar{\tau}^{1}$. Formally, we can represent this as $\bar{\tau}^{1}=\varphi\left(\bar{\tau}^{2}\right)$ and $\bar{\tau}^{2}=\varphi\left(\bar{\tau}^{1}\right)$, where $\varphi(\cdot)$ is a strictly increasing function. Then substituting $\varphi\left(\bar{\tau}^{1}\right)$ for $\bar{\tau}^{2}$ and $\varphi\left(\bar{\tau}^{2}\right)$ for $\bar{\tau}^{1}$ in the above inequality we have $\varphi\left(\bar{\tau}^{1}\right)>\varphi\left(\bar{\tau}^{2}\right)$. But because $\varphi(\cdot)$ is a strictly increasing function, this implies that $\bar{\tau}^{1}>\bar{\tau}^{2}$. Contradiction.

This result follows from the simple fact that all countries in $A$ have identical technologies, and each country's tariff is an increasing function of all others (in $A$ ). Of course, a symmetrical result holds for the countries in $B$. Now that we have this result in place, we know that for each equilibrium all countries in $A$ will set the same equilibrium tariff. Henceforth, we will use $\bar{\tau}^{a}$ to refer to the common equilibrium tariff set by all countries in $A$.

The next result shows that the equilibrium of the tariff game between countries in $A$ has a unique Nash equilibrium tariff $\bar{\tau}^{a}$, and that $\bar{\tau}^{a}$ is decreasing in $x$.

Proposition 3. For any number of countries in the North, $x$, the tariff game $\Gamma\left(\tau^{b}\right)$ admits a unique symmetric Nash equilibrium. The unique symmetric equilibrium tariff, $\bar{\tau}^{a}$, is decreasing in $x$, is independent of $\tau^{b}$ and independent of $y$.

Since tariff best-response functions are continuous, for more than one symmetrical equilibrium point to exist, it would have to be the case that $\partial \tau^{i} / \partial \tau^{j}>1$ for any $i, j \in A$ between two of the equilibrium points. The proof rules out the possibility of $\partial \tau^{i} / \partial \tau^{j}>1$ and so proves uniqueness. The intuition behind this result is as follows. If we think in terms of another country in $A$ lowering tariffs, we see that country $a$ restores import share 
by lowering its tariff, but obtains a terms-of-trade gain if it lowers its tariff by less than its trade partners. Hence country $a$ 's best-response to a tariff change of another country in $A$ is less than one-for-one.

The result that $\bar{\tau}^{a}$ is decreasing in $x$ is easy to see, once it is realized that (starting at the unique equilibrium) country $a$ responds to an increase in imports by all other countries in $A$ by lowering its own tariff so that its own imports increase. It does not matter to country $a$ whether it loses import share to other countries in $A$ because one (or more) existing country in $A \backslash a$ lowers its tariff or because an additional country is added to $A$ and that country's imports are positive. Country $A$ 's response in either case is to recover part of its import share by lowering its tariff.

Finally, the fact that $\bar{\tau}^{a}$ is not dependent on $\tau^{b}$ and $y$ follows (given the assumptions about technology and preferences) on the symmetry of equilibrium. Recall from our earlier results that changes in $\bar{\tau}^{a}$ are brought about when a given change brings about a change in country $a$ 's import share and it is motivated to change $\bar{\tau}^{a}$ in order to recover part of that share. But from the perspective of countries in $A$, a change in $\tau^{b}$ or $y$ will only affect the change in the volume of trade. If all countries in $A$ are setting the same tariff, the share of trade will not be affected. Thus, there is no incentive to change the tariff in response to a change in $\tau^{b}$ or $y$. This property of the model is convenient for analysis of the general tariff game as we shall see below.

This concludes our characterization of equilibrium for the tariff game of the North. The characterization, of course, extends directly to equilibrium of the tariff game of the South. We may now proceed to characterize equilibrium in both regions simultaneously, thus characterizing equilibrium for the general tariff game.

\subsection{Characterization of Equilibrium for The General Tariff Game}

In this section we consider the outcome of the general tariff game in which all countries in $N$ simultaneously and without communicating set their tariff. Given the sequence of events set out in Section 2, we know that the general tariff game has a Nash equilibrium. From Propositions 1-3 we are now able to characterize that equilibrium.

So far we have defined a tariff game $\Gamma\left(\tau^{b}\right)$, played by all countries in $A$ taking as 
given a unique tariff $\tau^{b}$ set by all countries in $B$. For this game, we have obtained a unique equilibrium tariff for the countries in $A, \bar{\tau}^{a}$, and shown that this tariff must be declining in the number of countries, $x$, in $A$. We have also shown that, given our assumptions on preferences and technology, $\bar{\tau}^{a}$ must be independent of both the level of $\tau^{b}$ and of the number of countries, $y$, in $B$.

Symmetrically, we may define a tariff game $\Gamma\left(\tau^{a}\right)$, played by all countries in $B$ and taking as given the tariff vector in which all countries in $A$ set a tariff $\tau^{a}$. From Propositions 1, 2 and 3, for any $\tau^{a}$ there must exist a unique equilibrium tariff, $\bar{\tau}^{b}$, which is decreasing in $y$ and independent of $\tau^{a}$ and $x$.

We may now bring the characterization of equilibrium for each region together and characterize the equilibrium of the general tariff game. ${ }^{15}$

Proposition 4. There exists a unique symmetric equilibrium of the general tariff game. The unique symmetric equilibrium tariff of countries in $A, \bar{\tau}^{a}$, is decreasing in $x$, is independent of $\bar{\tau}^{b}$ and is independent of $y$. The unique symmetric equilibrium tariff of countries in $B, \bar{\tau}^{b}$, is decreasing in $y$, is independent of $\bar{\tau}^{a}$ and is independent of $x$.

It is straight forward to solve for the unique trading equilibrium of the tariff game in each region and, in the process of doing so, verify that the equilibrium of the general tariff game is unique. An example of such a solution is presented in Section 5 below.

\subsection{Increase of countries in one region}

Let us now focus on the trading equilibrium characterized above. We can perform comparative statics on the equilibrium, focusing in particular on the effect of changes in the number of countries in one region. The properties of equilibrium presented in the next result are easily obtained by observing the effect of a change in $x$ on $\bar{\tau}^{a}$ and $y$ on $\bar{\tau}^{b}$ respectively.

\footnotetext{
${ }^{15}$ It is well known that, for ad valorem tariffs in a two country tariff war, there is a continuum of Nash equilibria of a tariff game in which no trade takes place. See Dixit (1987). The same result would hold in the present many-country setting. The following result characterizes the unique equilibrium of the general tariff game in which there is trade.
} 
Proposition 5. The unique trading equilibrium exhibits the following comparative statics properties:

(i) $E_{\mu^{a}}^{a} d \mu^{a} / d y>0$ and $E_{\mu^{b}}^{b} d \mu^{b} / d x>0$;

(ii) $E_{\mu^{a}}^{a} d \mu^{a} / d x$ is ambiguous and $E_{\mu^{b}}^{b} d \mu^{b} / d y$ is ambiguous.

An increase in $y$ has the effect of increasing imports by all countries in $B$ of good 1 and bringing about a reduction in $\bar{\tau}_{b}$. Both of these effects improve country $a$ 's terms-of-trade and hence its welfare (see the first equation in 3.11).

An increase in $x$ has the effect of increasing imports by all countries in $A$ of good 2 and bringing about a reduction in $\bar{\tau}_{a}$. Both of these effects improve country $b$ 's terms-of-trade and hence its welfare (see the second equation in 3.11).

The effect on countries in $A$ of an increase in $x$ is ambiguous; there are static efficiency gains associated with a fall $\bar{\tau}_{a}$ but at the same time this brings about a reduction in country $a$ 's terms-of-trade and hence welfare. The same type of ambiguity is created for the countries in $B$ from an increase in $y$.

\subsection{Increase of countries in both regions}

We are now in a position to study the effects of a simultaneous increase in the number of countries in both regions. We can define any world economy in terms of the ratio of countries in the South to countries in the North. For example, say that $x=4$ and $y=6$. Then we have $r=3 / 2$. Now if we fix $r$ then we can study the replication of the world economy. Since the response of the economy in equilibrium to replication is monotonic, we can define replication simply in terms of an increase in $x$.

Proposition 6. Assume an initial symmetric equilibrium of the general tariff game. As the economy is replicated, equilibrium tariffs $\bar{\tau}^{a}$ and $\bar{\tau}^{b}$ decrease monotonically and as the number of replications becomes large equilibrium import volumes $M^{A}$ and $M^{B}$ converge towards efficient levels; the symmetric equilibrium of the general tariff game converges towards world efficiency/free trade.

From the results that have already been established, the implications for world welfare 
of replication follow naturally. By Proposition 6, as the international trading economy is replicated, import volumes increase monotonically as equilibrium tariffs fall. Eventually, as $x$ becomes large, equilibrium tariffs tend towards zero, and in the limit the outcome of world efficiency (free trade) is attained.

\section{An Example}

We see from Proposition 5 that the distributional implications of replicating the economy are unclear. While an increase in the number of countries in the other region improves welfare, the effect of increasing in the number of countries in a country's own region are ambiguous. To show that sharper predictions about the distributional implications of replication can be obtained, we now solve the model for a simple exchange economy with unit boundary endowments ; each country in $A$ is endowed with a unit of good 1 and each country in $B$ is endowed with a unit of good 2 . We will also assume the following symmetrical Cobb-Douglas preferences:

$$
u^{i}=\Pi_{j \in\{1,2\}}\left(z_{j}^{i}\right)^{1 / 2}, i \in N
$$

where $z_{j}^{i}$ represents the Marshallian demand of good $j$ in country $i$. Then the unique symmetric equilibrium tariffs are as follows:

$$
\bar{\tau}^{a}=\frac{1}{x-1} ; \bar{\tau}^{b}=\frac{1}{y-1} .
$$

Solving for terms-of-trade $q$ using (2.4), we obtain the following reduced form expression:

$$
q(x, y)=q\left(\bar{\tau}^{a}(x), \bar{\tau}^{b}(y)\right)=\frac{y(y-1)(x-\alpha)}{x(x-1)(y-\alpha)}
$$

Using this expression and equilibrium tariffs in the indirect utility function, we have

$$
\begin{aligned}
u^{a}(x, y) & =u^{a}\left(q\left(\bar{\tau}^{a}(x), \bar{\tau}^{b}(y)\right), \bar{\tau}^{a}(x)\right) \\
& =\frac{x(1-\alpha)\left(\frac{y(y-1) \alpha}{x(y-\alpha)}\right)^{\alpha}\left(\frac{x(1-\alpha)}{x-\alpha}\right)^{-\alpha}}{x-\alpha} .
\end{aligned}
$$




\subsection{Increase of countries in one region}

Based on this example, we are now able to obtain the following sharper result concerning the implications of an increase in the number of countries in one region:

Proposition 7. Assume an exchange economy with unit boundary endowments and symmetrical Cobb-Douglas preferences.

(i) $d u^{a}(x, y) / d x<0$ and is decreasing in the ratio of $y$ to $x$;

(ii) $d u^{a}(x, y) / d y>0$ and is decreasing in the ratio of $y$ to $x$.

This result is obtained by performing comparative statics on (5.1). Part (i) confirms the general result in Proposition 5 for the example; an increase in $y$ has the effect of bringing about a reduction in $\bar{\tau}_{b}$ and increasing imports of good 1 by the countries in $B$. Both of these effects improve country $a$ 's terms-of-trade and hence its welfare; see $u^{a}(x, y)$. While the effect of an increase in $y$ on $u^{a}(x, y)$ is positive, it impact diminishes as $y$ increases. This effect is easy to see by inspection of $u^{a}(x, y)$, and makes intuitive sense when it is realized that the effect is driven by an increase of imports of primary products in $u^{a}$, and the imports in turn are valued less highly at the margin as $y$ increases.

An increase in $x$ has the opposite effect, of increasing imports of primary products by the North and bringing about a reduction of $\bar{\tau}_{a}$. Both of these effects contribute to a reduction in $a$ 's terms-of-trade and hence welfare. The negative impact on welfare increases with $x$, since it is driven by a decrease of primary product imports in $u^{a}$, and primary products in turn are valued more highly at the margin as $x$ increases.

\subsection{Increase of countries in both regions}

The following result obtains sharper predictions about replication of the world economy based on the example of the present section.

Proposition 8. Assume an initial trading equilibrium for which $x \geq 2, x \geq 2$ and $r=y / x$.

World efficiency implications of replication: The higher is $x$ then the higher is world 
welfare, and world welfare is maximized as $x \rightarrow \infty$.

Distributional implications of replication: There exists a value $r^{\prime}>1$ such that if $r=r^{\prime}$ then a given increase in $x$ will leave $u^{a}(x, r x)$ unchanged; if $r<r^{\prime}$ then an increase in $x$ will bring about an increase of $u^{a}(x, r x)$ and if $r>r^{\prime}$ then an increase in $x$ will bring about a decrease of $u^{a}(x, r x)$.

From the results that have already been established, the implications for world welfare of replication follow naturally. By Proposition 6, as the international trading economy is replicated, export volumes increase monotonically as equilibrium tariffs fall. Trade flows increase monotonically from one region to the other and world welfare increases monotonically as well. Eventually, as $x$ becomes large, equilibrium tariffs $\bar{\tau}^{a}=1 /(x-1)$ and $\bar{\tau}^{b}=1 /(r x-1)$ tend towards zero, and in the limit the outcome of world efficiency (free trade) is attained.

The distributional implications are more surprising but they can be understood as follows. The higher the value of $r$, the more scarce are manufactures (endowments in $A$ ) relative to primary products (endowments in $B$ ). Country $a$ is able to exploit this scarcity because the import elasticity of demand for its export is relatively low in equilibrium. Consequently, country $a$ sets a relatively high tariff in equilibrium compared to country $b$, and as a result $u^{a}(x, r x)>u^{b}(r x, x)$. If $r$ is relatively high then the terms-of-trade effects of its relatively high tariff may be sufficient to ensure that $u^{a}(x, r x)$ is above its free trade level.

As $x$ is increased this reduces the relative scarcity of country $a$ 's good, reducing $a$ 's equilibrium tariff. This has two effects on $u^{a}(x, r x)$. The static efficiency gains of tariff reduction increase $u^{a}(x, r x)$. On the other hand, the tariff reduction may also reduce $a$ 's terms-of-trade, reducing $u^{a}(x, r x)$. As $m$ is increased, $u^{a}(x, r x)$ converges to its efficient (free trade) level. If at low levels of $m, r<r^{\prime}$ then $u^{a}(x, r x)$ converges to its efficient free trade level from below; the static efficiency effects of tariff reduction dominate. But, if $r>r^{\prime}$ then $u^{a}(x, r x)$ converges to its free trade level from above (while $u^{b}(x, r x)$ converges to its efficient/free trade level from below). 


\section{Summary and Conclusions}

For a model in which the world market is characterized as having two regions, and the tariff game between countries in one region is supermodular, the world economy responds in a predictable way to a change in its underlying regional structure. This offers an advance over conventional analysis in international trade which typically compares two 'snapshots,' one of autarky, or a Nash equilibrium in which trade is restricted, and the other of free trade. As explained in the Introduction, our framework yields insights in two areas of international trade. Each will be taken in turn and their implications discussed.

First we have distributional implications of changes in the number of countries in one region. Countries in each region compete to supply a homogeneous good to the other region. The fewer competitors a country has in the supply of its good, the better its terms of trade over imports from the other region. The introduction of additional countries in one region has beneficial terms of trade effects and these benefits are reaped by the countries in the other region. Given that in the world market there are a larger number of developing countries than developed countries, where levels of development may be correllated with types of goods exported, the model may provide a new way of understanding why developing countries tend to get poorer terms-of-trade on world markets.

Second, as the international trading economy is replicated, equilibrium tariff levels fall and trade volumes increase monotonically; equilibrium converges to the efficient free trade equilibrium. A complete characterization is presented of the relationship between market structure and market efficiency based on strategic interaction of country governments. Our example suggests surprising distributional implications of replication. As the world economy is replicated, the country whose exports are relatively scarce on world markets becomes worse off.

The framework of the present paper could be adapted to any situation in which the international market has two regions (or sides, where the number of sides is determined by the number of goods traded) and the actions of agents in one region (side) are strategic complements. ${ }^{16}$ It seems reasonable to suggest that the intuition underpinning this

\footnotetext{
${ }^{16}$ Amir and Bloch (2004) show that for a strategic market game the results extend to a situation where
} 
relationship extends to more complex environments in which the market has more sides as well.

The analysis could be extended usefully in a number of directions. One would be to integrate intra-industry trade into the framework. A natural way to do this would be, following Helpman and Krugman (1985), to assume that manufactures are horizontally differentiated while the agricultural good is homogeneous. This would enrich the results while preserving the feature of the model that the more numerous primary product producers undermine each others' terms of trade.

As mentioned in the introduction, the model also offers a useful way to consider various different types of trade agreement in a framework where there are a larger number of countries distributed across regions. Building on the standard model of a tariff war, the literature on multilateral trade liberalization typically focuses on a situation where there are just two countries. The literature on preferential trade agreements typically focuses on models where there are three countries. Bagwell and Staiger (2002) present a general framework for analysis of the world trading system (and see Staiger 1995 for a comprehensive review of the literature). The present paper suggests that additional insights are available when a larger number of countries are introduced.

\section{A. Appendix}

\section{A.1. Proof of Propositions}

Proof of Proposition 1. We will work with the case of country $a$. The case of country $b$ is analogous. Rewrite (4.1), the first order condition for government $a$ 's problem, as

$$
\psi_{\tau^{a}}^{a}=s^{a}-\tau^{a}\left(\sum_{i \in A \backslash a} s^{i} \varepsilon^{i}+\sum_{i \in B} s^{i} \varepsilon^{i}-1\right)=0 .
$$

actions across the two sides of the market are strategic substitutes. Preliminary work to generalize the results of this present paper suggest that the same holds in a general tariff game setting. 
It remains only to show that $a$ 's objective function is quasi-concave; $\partial \psi_{\tau^{a}}^{a} / \partial \tau^{a}<0$ whenever $\psi_{\tau^{a}}^{a}=0$. Using $d s^{i} / d \tau^{j}$ do denote the total derivative of $s^{i}$ w.r.t. $\tau^{j}$, we have

$$
\begin{aligned}
\frac{\partial \psi_{\tau^{a}}^{a}}{\partial \tau^{a}}= & \frac{d s^{a}}{d \tau^{a}}-\left(\sum_{i \in A \backslash a} s^{i} \varepsilon^{i}+\sum_{i \in B} s^{i} \varepsilon^{i}-1\right) \\
& +s^{a}\left(\sum_{i \in A \backslash a} s^{i} \varepsilon^{i} \theta^{i}-\sum_{i \in B} s^{i} \varepsilon^{i} \theta^{i}\right) \frac{\phi^{a}}{\Delta} \frac{\tau^{a}}{1+\tau^{a}} \\
& -\tau^{a}\left(\sum_{i \in A \backslash a} \varepsilon^{i} \frac{d s^{i}}{d \tau^{a}}+\sum_{i \in B} \varepsilon^{i} \frac{d s^{i}}{d \tau^{a}}\right) .
\end{aligned}
$$

where $\theta^{i}=\frac{p^{i}}{\varepsilon^{i}} \frac{\partial \varepsilon^{i}}{\partial p^{i}}$. Since at interior solutions optimal intervention by country a requires $\sum_{i \in B} s^{i} \varepsilon^{i}-1>0$ [need to check this] (which implies $\Delta>1$ ) and A1 implies that $\theta^{i}=0$ for all $i$ (since $\varepsilon^{i}$ is constant at $\varepsilon$ ) the term in brackets on the first line is positive and the terms in brackets on the second line are equal to zero. Also, since all countries in $B$ set the same tariff, $\tau^{b}$, it must be that $s^{i}$ is the same for all $i \in B$. By symmetry, each country in $B$ must respond symmetrically to a change in $\tau^{a}$ and so $d s^{i} / d \tau^{a}=0$ for all $i \in B$. Therefore, we only have to show that $d s^{a} / d \tau^{a}<0$ and $d s^{i} / d \tau^{a}>0$, all $i \in A \backslash a$.

We sign $d s^{a} / d \tau^{a}$ first. Totally differentiating the expression for $s^{a}$, we have

$$
\hat{s}^{a}\left(\tau^{a}\right)=\left(1-s^{a}\right) \hat{m}^{a}-\sum_{i \in A \backslash a} s^{i} \hat{m}^{i} .
$$

Since $d \tau^{i}=0$ for all $\tau^{i} \neq \tau^{a}$, substitution of (3.6) into (3.3) yields

$$
\begin{aligned}
\hat{m}^{a} & =\left(\varepsilon^{a} s^{a}-\Delta\right) \frac{\phi^{a}}{\Delta} \frac{d \tau^{a}}{1+\tau^{a}} \\
& =-\left(\sum_{i \in A \backslash a} s^{i} \varepsilon^{i}+\sum_{i \in B} s^{i} \varepsilon^{i}-1\right) \frac{\phi^{a}}{\Delta} \frac{d \tau^{a}}{1+\tau^{a}}<0 .
\end{aligned}
$$

Also,

$$
\hat{m}^{i}=\varepsilon^{i} s^{a} \frac{\phi^{a}}{\Delta} \frac{d \tau^{a}}{1+\tau^{a}}>0, \forall i \in A \backslash a .
$$

so $\hat{s}^{a}<0$. Then $d s^{a} / d \tau^{a}=s^{a} \hat{s}^{a} / d \tau^{a}<0$.

We now sign $d s^{i} / d \tau^{a}$. Totally differentiating the expression for $s^{i}$, we have 


$$
\begin{aligned}
\hat{s}^{i}\left(\tau^{a}\right)= & \left(1-s^{i}\right) \hat{m}^{i}-s^{a} \hat{m}^{a}-\sum_{j \in A \backslash\{a \cup i\}} s^{j} \hat{m}^{j} \\
= & s^{a}\left(1-s^{i}\right) \varepsilon^{i} \frac{\phi^{a}}{\Delta} \frac{d \tau^{a}}{1+\tau^{a}} \\
& +s^{a}\left(\sum_{j \in A \backslash a} s^{j} \varepsilon^{j}+\sum_{j \in B} s^{j} \varepsilon^{j}-1\right) \frac{\phi^{a}}{\Delta} \frac{d \tau^{a}}{1+\tau^{a}} \\
& -s^{a} \sum_{j \in A \backslash\{a \cup i\}} s^{j} \varepsilon^{j} \frac{\phi^{a}}{\Delta} \frac{d \tau^{a}}{1+\tau^{a}} \\
= & s^{a}\left(\varepsilon^{i}+\left(\sum_{j \in B} s^{j} \varepsilon^{j}-1\right)\right) \frac{\phi^{a}}{\Delta} \frac{d \tau^{a}}{1+\tau^{a}}>0 .
\end{aligned}
$$

Then

$$
\frac{d s^{i}}{d \tau^{a}}=s^{i} \hat{s}^{i}\left(\tau^{a}\right) \frac{1}{d \tau^{a}}=s^{i} s^{a}\left(\varepsilon^{i}+\left(\sum_{j \in B} s^{j} \varepsilon^{j}-1\right)\right) \frac{\phi^{a}}{\Delta} \frac{1}{1+\tau^{a}}>0 .
$$

So $d s^{i} / d \tau^{a}>0, i \in A \backslash a$, as required.

Proof of Lemma 1. We evaluate the response of $\tau^{a}$ to a change in any of the tariffs in $\boldsymbol{\tau}^{-a}$; w.o.l.o.g., take $\tau^{1}, a \neq 1$. The aim is to show that $\partial \tau^{a} / \partial \tau^{1}>0$. By the implicit function theorem,

$$
\frac{\partial \tau^{a}}{\partial \tau^{1}}=-\frac{\partial \psi_{\tau^{a}}^{a} / \partial \tau^{1}}{\partial \psi_{\tau^{a}}^{a} / \partial \tau^{a}}
$$

Since we know from the proof of Proposition 1 that $\partial \psi_{\tau^{a}}^{a} / \partial \tau^{a}<0$, it remains only to show that $\partial \psi_{\tau^{a}}^{a} / \partial \tau^{1}>0$. First, we obtain the following expression for $\partial \psi_{\tau^{a}}^{a} / \partial \tau^{1}$ :

$$
\begin{aligned}
\frac{\partial \psi_{\tau^{a}}^{a}}{\partial \tau^{1}}= & \frac{d s^{a}}{d \tau^{1}}-\tau^{a}\left(\sum_{i \in A \backslash a} s^{i} \frac{\partial \varepsilon^{i}}{\partial p^{i}} \frac{\partial p^{i}}{\partial \tau^{1}}+\sum_{i \in B} \frac{\partial \varepsilon^{i}}{\partial p^{i}} \frac{\partial p^{i}}{\partial \tau^{1}}\right. \\
& \left.+\sum_{i \in A \backslash a} s^{i} \frac{\partial \varepsilon^{i}}{\partial \tau^{1}}+\sum_{i \in B} s^{i} \frac{\partial \varepsilon^{i}}{\partial \tau^{1}}\right) \\
& -\tau^{a}\left(\sum_{i \in A \backslash a} \varepsilon^{i} \frac{d s^{i}}{d \tau^{1}}+\sum_{i \in B} \varepsilon^{i} \frac{d s^{i}}{d \tau^{1}}\right)
\end{aligned}
$$

By A1, since $\partial \varepsilon^{i} / \partial p^{i}=\partial \varepsilon^{i} / \partial \tau^{1}=0$, the terms in the first brackets disappear. Also, since all countries in $B$ set $\tau^{b}, \sum_{i \in B} \varepsilon^{i} \frac{d s^{i}}{d \tau^{1}}=0$. Therefore,

$$
\frac{\partial \psi_{\tau^{a}}^{a}}{\partial \tau^{1}}=\frac{d s^{a}}{d \tau^{1}}-\tau^{a} \varepsilon \sum_{i \in A \backslash a} \frac{d s^{i}}{d \tau^{1}}
$$


where we have again used A1 to set $\varepsilon^{i}=\varepsilon$, all $i \in A$.

Now, we already know (from the proof of Proposition 1) that $d s^{i} / d \tau^{a}>0$ and this is equivalent to showing that $d s^{a} / d \tau^{1}>0$. So therefore it remains only to show that $\sum_{i \in A \backslash a} d s^{i} / d \tau^{1}<0$.

Since

$$
\frac{d s^{1}}{d \tau^{1}}<0 \text { while } \frac{d s^{i}}{d \tau^{1}}>0, i \neq 1
$$

the aim is to show that $d s^{1} / d \tau^{1}<-\sum_{i \in A \backslash\{a \cup 1\}} d s^{i} / d \tau^{1}(<0)$.

From the proof of Proposition 1, we know that

$$
\hat{s}^{1}=\left(1-s^{1}\right) \hat{m}^{1}-\sum_{i \in A \backslash 1} s^{i} \hat{m}^{i}<0 .
$$

Substituting for $\hat{m}^{1}$ and $\hat{m}^{i}$ by using (3.6) in (3.3) yields

$$
\begin{aligned}
\hat{s}^{1}\left(\tau^{1}\right)= & -\left(1-s^{1}\right)\left(\sum_{i \in A \backslash 1} \varepsilon^{i} s^{i}+\sum_{i \in B} \varepsilon^{i} s^{i}-1\right) \frac{\phi^{1}}{\Delta} \frac{d \tau^{1}}{1+\tau^{1}} \\
& -\sum_{i \in A \backslash 1} \varepsilon^{i} s^{i} s^{1} \frac{\phi^{1}}{\Delta} \frac{d \tau^{1}}{1+\tau^{1}} \\
= & -\left(\sum_{i \in A \backslash 1} \varepsilon^{i} s^{i}+\sum_{i \in B} \varepsilon^{i} s^{i}-1\right) \frac{\phi^{1}}{\Delta} \frac{d \tau^{1}}{1+\tau^{1}}+s^{1}\left(\sum_{i \in B} \varepsilon^{i} s^{i}-1\right) \frac{\phi^{1}}{\Delta} \frac{d \tau^{1}}{1+\tau^{1}} \\
= & -\sum_{i \in A \backslash 1} \varepsilon^{i} s^{i} \frac{\phi^{1}}{\Delta} \frac{d \tau^{1}}{1+\tau^{1}}-\left(1-s^{1}\right)\left(\sum_{i \in B} \varepsilon^{i} s^{i}-1\right) \frac{\phi^{1}}{\Delta} \frac{d \tau^{1}}{1+\tau^{1}}
\end{aligned}
$$

Then

$$
\frac{d s^{1}}{d \tau^{1}}=s^{1} \hat{s}^{1}\left(\tau^{1}\right) \frac{1}{d \tau^{1}}=-\left(\sum_{i \in A \backslash 1} \varepsilon^{i} s^{i}+\left(1-s^{1}\right)\left(\sum_{i \in B} s^{i} \varepsilon^{i}-1\right)\right) s^{1} \frac{\phi^{1}}{\Delta} \frac{1}{1+\tau^{1}} .
$$

Now we can compare $d s^{1} / d \tau^{1}$ to $-\sum_{i \in A \backslash\{a \cup 1\}} d s^{i} / d \tau^{1}$, where

$$
\frac{d s^{i}}{d \tau^{1}}=s^{i}\left(\varepsilon^{i}+\sum_{i \in B} s^{i} \varepsilon^{i}-1\right) s^{1} \frac{\phi^{1}}{\Delta} \frac{1}{1+\tau^{1}}
$$


so that

$$
\begin{aligned}
-\sum_{i \in A \backslash\{a \cup 1\}} d s^{i} / d \tau^{1} & =-\sum_{i \in A \backslash\{a \cup 1\}}\left(\varepsilon^{i} s^{i}+s^{i}\left(\sum_{i \in B} s^{i} \varepsilon^{i}-1\right)\right) s^{1} \frac{\phi^{1}}{\Delta} \frac{1}{1+\tau^{1}} \\
& =-\left(\sum_{i \in A \backslash\{a \cup 1\}} \varepsilon^{i} s^{i}+\left(1-s^{1}-s^{a}\right)\left(\sum_{i \in B} s^{i} \varepsilon^{i}-1\right)\right) s^{1} \frac{\phi^{1}}{\Delta} \frac{1}{1+\tau^{1}} \\
& >d s^{1} / d \tau^{1} .
\end{aligned}
$$

as required.

Proof of Proposition 3. We know from Proposition 2 that at any equilibrium of the game $\Gamma\left(\tau^{b}\right)$, all countries in $A$ set the same tariff; $\bar{\tau}^{1}=\ldots=\bar{\tau}^{a}=\ldots=\bar{\tau}^{x}$. We will now show that there can be only one such equilibrium. In view of the symmetry of every Nash equilibrium and differentiability of each country's best-response tariff function, to show uniqueness of Nash equilibrium for every $x$, it suffices to show that at every Nash equilibrium we have $\partial \tau^{i} / \partial \tau^{j}<1$. Since each country's best-response function is continuous, for there to be more than one point at which $\bar{\tau}^{1}=\ldots=\bar{\tau}^{a}=\ldots=\bar{\tau}^{x}$, it must be the case that $\partial \tau^{j} / \partial \tau^{i}>1$ for any two $i, j \in A$, between two equilibrium points. Without loss of generality, let $j=a$ and $j=1$. Then from Lemma 1 we may write

$$
\frac{\partial \tau^{a}}{\partial \tau^{1}}=-\frac{\partial \psi_{\tau^{a}}^{a} / \partial \tau^{1}}{\partial \psi_{\tau^{a}}^{a} / \partial \tau^{a}}
$$

The aim now is to show that $\partial \tau^{a} / \partial \tau^{1}<1$. (We already know from Lemma 1 that $\partial \tau^{a} / \partial \tau^{1}>0$.) From the proof of Lemma 1, we have

$$
-\frac{\partial \psi_{\tau^{a}}^{a} / \partial \tau^{1}}{\partial \psi_{\tau^{a}}^{a} / \partial \tau^{a}}=\frac{-\frac{d s^{a}}{d \tau^{1}}+\tau^{a} \varepsilon \sum_{i \in A \backslash a} \frac{d s^{i}}{d \tau^{1}}}{\frac{d s^{a}}{d \tau^{a}}-\left(\sum_{i \in A \backslash a} \varepsilon s^{i}+\sum_{i \in B} \varepsilon s^{i}-1\right)-\tau^{a} \varepsilon \sum_{i \in A \backslash a} \frac{d s^{i}}{d \tau^{a}}}
$$

We will now show that the numerator is smaller than the denominator by comparing terms. First observe that $d s^{a} / d \tau^{a} \leq-d s^{a} / d \tau^{1}$. To see this, observe from the proof of Lemma 1 that,

$$
\frac{d s^{a}}{d \tau^{a}}=-\left(\sum_{i \in A \backslash a} \varepsilon^{i} s^{i}+\left(1-s^{a}\right)\left(\sum_{i \in B} \varepsilon^{i} s^{i}-1\right)\right) s^{a} \frac{\phi^{a}}{\Delta} \frac{1}{1+\tau^{a}}
$$

while

$$
-\frac{d s^{a}}{d \tau^{1}}=-\left(\varepsilon^{a} s^{a}+s^{a}\left(\sum_{i \in B} \varepsilon^{i} s^{i}-1\right)\right) s^{1} \frac{\phi^{1}}{\Delta} \frac{1}{1+\tau^{1}} .
$$


The equilibrium is symmetric and so $s^{a} \frac{\phi^{a}}{\Delta} \frac{1}{1+\tau^{a}}=s^{1} \frac{\phi^{1}}{\Delta} \frac{1}{1+\tau^{1}}$. Also, it must be the case that $x \geq 2$ for the game $\Gamma\left(\tau^{b}\right)$ to be meaningful and so $s^{1}=s^{a} \leq \frac{1}{2}$. It is then immediate that the term inside the bracket on the right hand side of $d s^{a} / d \tau^{a}$ is larger than the term inside the bracket of $d s^{a} / d \tau^{1}$ for $x>2$ and equal for $x=2$.

Next recall from the proof of Proposition 1 that the second term in the denominator is positive; $\left(\sum_{i \in A \backslash a} \varepsilon^{i} s^{i}+\sum_{i \in B} \varepsilon^{i} s^{i}-1\right)>0$.

Finally, we show that $-\sum_{i \in A \backslash a} \frac{d s^{i}}{d \tau^{a}}<\sum_{i \in A \backslash a} \frac{d s^{i}}{d \tau^{1}}$. From the proof of Lemma 1,

$$
-\sum_{i \in A \backslash a} \frac{d s^{i}}{d \tau^{a}}=-\left(\sum_{i \in A \backslash a} \varepsilon^{i} s^{i}+\left(1-s^{a}\right)\left(\sum_{i \in B} s^{i} \varepsilon^{i}-1\right)\right) s^{a} \frac{\phi^{a}}{\Delta} \frac{1}{1+\tau^{a}},
$$

while, again from the proof of Lemma 1,

$$
\sum_{i \in A \backslash a} \frac{d s^{i}}{d \tau^{1}}=-\left(\varepsilon^{a} s^{a}+s^{a}\left(\sum_{i \in B} s^{i} \varepsilon^{i}-1\right)\right) s^{1} \frac{\phi^{1}}{\Delta} \frac{1}{1+\tau^{1}} .
$$

This completes the proof that $\partial \tau^{a} / \partial \tau^{1}<1$.

We now prove that the unique equilibrium tariff is decreasing in $x$. The aim is to show that $\partial \tau^{a} / \partial x<0$. Again, by the implicit function theorem,

$$
\frac{\partial \tau^{a}}{\partial x}=-\frac{\partial \psi_{\tau^{a}}^{a} / \partial x}{\partial \psi_{\tau^{a}}^{a} / \partial \tau^{a}}
$$

Since we know from the proof of Proposition 1 that $\partial \psi_{\tau^{a}}^{a} / \partial \tau^{a}<0$, it remains only to show that $\partial \psi_{\tau^{a}}^{a} / \partial x<0$. First, we obtain the following expression for $\partial \psi_{\tau^{a}}^{a} / \partial x$ :

$$
\begin{aligned}
\frac{\partial \psi_{\tau^{a}}^{a}}{\partial x}= & \frac{d s^{a}}{d x}-\tau^{a}\left(\sum_{i \in A \backslash a} s^{i} \frac{\partial \varepsilon^{i}}{\partial p^{i}} \frac{\partial p^{i}}{\partial x}+\sum_{i \in B} \frac{\partial \varepsilon^{i}}{\partial p^{i}} \frac{\partial p^{i}}{\partial x}\right. \\
& \left.+\sum_{i \in A \backslash a} s^{i} \frac{\partial \varepsilon^{i}}{\partial x}+\sum_{i \in B} s^{i} \frac{\partial \varepsilon^{i}}{\partial x}\right) \\
& -\tau^{a}\left(\sum_{i \in A \backslash a} \varepsilon^{i} \frac{d s^{i}}{d x}+\sum_{i \in B} \varepsilon^{i} \frac{d s^{i}}{d x}\right) .
\end{aligned}
$$

An increase in $x$ must bring about a reduction in $s^{a} ; d s^{a} / d x<0$. Since $\varepsilon^{i}$ is fixed at $\varepsilon$, the terms in the first set of brackets are zero. And since $\sum_{i \in A} s^{i}=1$ while $s^{a}$ falls, it must be the case that $\sum_{i \in A \backslash a} \frac{d s^{i}}{d x}>0$. So $\partial \psi_{\tau^{a}}^{a} / \partial x<0$ as required. 
We adopt the same basic approach to show that $\bar{\tau}^{a}$ is independent of $\bar{\tau}^{b}$ and independent of $y$; i.e. $\partial \bar{\tau}^{a} / \partial \bar{\tau}^{b}=0$ and $\partial \bar{\tau}^{a} / \partial y=0$. We now show the case for $\partial \bar{\tau}^{a} / \partial \bar{\tau}^{b}=0$. Again, by the implicit function theorem,

$$
\frac{\partial \tau^{a}}{\partial \tau^{b}}=-\frac{\partial \psi_{\tau^{a}}^{a} / \partial \tau^{b}}{\partial \psi_{\tau^{a}}^{a} / \partial \tau^{a}} .
$$

Then to obtain the result, we only need to show that $\partial \psi_{\tau^{a}}^{a} / \partial \tau^{b}=0$. We have

$$
\begin{aligned}
\frac{\partial \psi_{\tau^{a}}^{a}}{\partial \tau^{b}}= & \frac{d s^{a}}{d \tau^{b}}-\tau^{a}\left(\sum_{i \in A \backslash a} s^{i} \frac{\partial \varepsilon^{i}}{\partial p^{i}} \frac{\partial p^{i}}{\partial \tau^{b}}+\sum_{i \in B} \frac{\partial \varepsilon^{i}}{\partial p^{i}} \frac{\partial p^{i}}{\partial \tau^{b}}\right. \\
& \left.+\sum_{i \in A \backslash a} s^{i} \frac{\partial \varepsilon^{i}}{\partial \tau^{b}}+\sum_{i \in B} s^{i} \frac{\partial \varepsilon^{i}}{\partial \tau^{b}}\right) \\
& -\tau^{a}\left(\sum_{i \in A \backslash a} \varepsilon^{i} \frac{d s^{i}}{d \tau^{b}}+\sum_{i \in B} \varepsilon^{i} \frac{d s^{i}}{d \tau^{b}}\right) .
\end{aligned}
$$

In a symmetric equilibrium, $d s^{a} / d \tau^{b}=0$; if all countries in $A$ set the same tariff, $\bar{\tau}^{a}$, then $s^{a}$ remains constant for any change in $\tau^{b}$ (even though the volume of trade will change with a change in $\left.\tau^{b}\right)$. Since, by A1, $\varepsilon^{i}$ is constant at $\varepsilon$, all terms in the first pair of brackets are zero. Finally, since $\tau^{b}$ is the same for all countries in a symmetric equilibrium, and the change in $\tau^{b}$ is the same across all countries as well, it must be that $d s^{i} / d \tau^{b}=0$ for all $i \in A \backslash a$ and all $i \in B$. Therefore, the terms in the second set of brackets is equal to zero as well. Thus, $\partial \psi_{\tau^{a}}^{a} / \partial \tau^{b}=0$. It follows that $\partial \tau^{a} / \partial \tau^{b}=0$.

Finally, exactly the same reasoning can be used to show that $\partial \psi_{\tau^{a}}^{a} / \partial y=0$, once it is recognized that $\sum_{i \in B} d s^{i} / d \tau^{b}=0$. This follows because $s^{i}=1$ for any value of $y$. It follows that $\partial \tau^{a} / \partial y=0$.

Proof of Proposition 4. Fix the number of countries in $B$ at $y$ and, for all countries in $B$, fix the tariff at the same level $\tau^{b}$. Also, fix the number of countries in $A$ at $x$. Then by Proposition 3, we know that there exists a unique symmetric equilibrium tariff rate $\bar{\tau}^{a}$ for all countries in $A$ and that $\bar{\tau}^{a}$ is decreasing in $x$. Fixing the tariff of all countries in $A$ at the equilibrium rate $\bar{\tau}^{a}$ we know, by application of Proposition 3 to the game $\Gamma\left(\tau^{a}\right)$, that there exists a unique equilibrium tariff rate $\bar{\tau}^{b}$ for all countries in $B$ and that $\bar{\tau}^{b}$ is decreasing in $y$. At tariffs $\bar{\tau}^{a}$ and $\bar{\tau}^{b}$ all countries set equilibrium tariffs and thus we have an equilibrium to the general tariff game. 
Proof of Proposition 5. By (3.11), the only way that $y$ affects $E_{\mu^{a}}^{a} d \mu^{a}$ is indirectly through its effect on $\hat{q}$. The effect on $\hat{q}$ of an increase in $y$ is indirect; by Proposition 3 , an increase in $y$ brings about a fall in $\bar{\tau}^{b}$ and, by (3.6), this in turn brings about a reduction in $\hat{q}$. We then see by (3.11) that the effect on $E_{\mu^{a}}^{a} d \mu^{a}$ is positive. The effect of a change in $x$ on $E_{\mu^{b}}^{b} d \mu^{b}$ is analogous.

We can also use (3.11) to see why the effect of $x$ on $E_{\mu^{a}}^{a} d \mu^{a}$ is ambiguous. While an increase in $x$ brings about a reduction in $\bar{\tau}^{a}$ and the direct effect of this on $E_{\mu^{a}}^{a} d \mu^{a}$ is positive, by (3.6) the effect of a fall in $\bar{\tau}^{a}$ is to increase $\hat{q}$ and the impact of this on $E_{\mu^{a}}^{a} d \mu^{a}$ is negative. The ambiguity of the effect of an increase in $y$ on $E_{\mu^{b}}^{b} d \mu^{b}$ can be established in a similar way.

Proof of Proposition 6. By Proposition 3, an increase in $x$ brings about a reduction in $\bar{\tau}^{a}$ and an increase in $y$ brings about a reduction in $\bar{\tau}^{b}$. As the economy is replicated, both $x$ and $y$ are increased in proportion and so both $\bar{\tau}^{a}$ and $\bar{\tau}^{b}$ fall. With a large number of replications, $\bar{\tau}^{a} \rightarrow 0$ and $\bar{\tau}^{b} \rightarrow 0$. Since tariffs are the only distortions in the world economy, both $m^{a}$ and $m^{b}$ converge to their efficient levels as all tariffs converge to zero. And since in symmetric equilibrium $m^{a}$ is representative of all $m^{i}$ in $M^{A}$, and $m^{b}$ is representative of all $m^{i}$ in $M^{B}$, aggregate import volumes must converge to efficient levels. Finally, by definition, as all tariffs converge towards zero the outcome converges towards world efficiency.

Proof of Proposition 7. Differentiation of $u^{a}\left(\bar{\tau}^{a}(x), \bar{\tau}^{b}(y)\right)$ with respect to $x$ yields

$$
\frac{d u^{a}\left(\bar{\tau}^{a}(x), \bar{\tau}^{b}(y)\right)}{d x}=-\frac{(1+x-2 \alpha) \alpha(1-\alpha)\left(\frac{y(y-1) \alpha}{x(y-\alpha)}\right)^{\alpha}\left(\frac{(1-\alpha) x}{x-\alpha}\right)^{-\alpha}}{(x-\alpha)^{2}}<0
$$

By inspection, $d u^{a}\left(\bar{\tau}^{a}(x), \bar{\tau}^{b}(y)\right) / d x$ is decreasing in $y$ if and only if $y(y-1) \alpha /(x(y-\alpha))$ is increasing in $y$, which holds for all feasible values of $\alpha, x$ and $y$.

Differentiation of $u^{a}\left(\bar{\tau}^{a}(x), \bar{\tau}^{b}(y)\right)$ with respect to $y$ yields

$$
\frac{d u^{a}\left(\bar{\tau}^{a}(x), \bar{\tau}^{b}(y)\right)}{d n}=\frac{(1-\alpha) \alpha^{2}\left(\frac{y(y-1) \alpha}{x(y-\alpha)}\right)^{\alpha-1}\left(\frac{(1-\alpha) x}{x-\alpha}\right)^{-\alpha}\left(y^{2}-2 y \alpha+\alpha\right)}{(x-\alpha)(y-\alpha)^{2}}>0 .
$$

By inspection or by taking the second derivative, $d u^{a}\left(\bar{\tau}^{a}(x), \bar{\tau}^{b}(y)\right) / d y$ is decreasing in $y$. 
Proof of Proposition 8. Efficiency implications of replication. In a trading equilibrium, by symmetry of the equilibrium world welfare is given by

$$
\begin{aligned}
x u^{a}(x, r y)+ & r x u^{b}(r x, x)= \\
& x \frac{x(1-\alpha)\left(\frac{y(y-1) \alpha}{x(y-\alpha)}\right)^{\alpha}\left(\frac{x(1-\alpha)}{x-\alpha}\right)^{-\alpha}}{x-\alpha}+r x \frac{r x(1-\alpha)\left(\frac{x(x-1) \alpha}{r x(x-\alpha)}\right)^{\alpha}\left(\frac{r x(1-\alpha)}{r x-\alpha}\right)^{-\alpha}}{r x-\alpha}
\end{aligned}
$$

We will show that the above expression is globally increasing in $x$. Differentiating, we get

$$
\begin{aligned}
\frac{d\left(x u^{a}(x, r x)+r x u^{b}(r x, x)\right)}{d x} & = \\
& \frac{1}{(x-\alpha)^{2}(r x-\alpha)^{2}} \times \\
& \left(x ( 1 - \alpha ) \left(r \alpha\left(\frac{r(r x-1) \alpha}{r x-\alpha}\right)^{\alpha-1}\left(\frac{x(1-\alpha)}{x-\alpha}\right)^{-\alpha} \Theta(x ; r, \alpha)\right.\right. \\
& \left.\left.+r\left(\frac{(r x-1) \alpha}{r x-\alpha}\right)^{-\alpha} \alpha\left(\frac{(x-1) \alpha}{r(x-\alpha)}\right)^{\alpha-1} \Phi(x ; r, \alpha)\right)\right)
\end{aligned}
$$

where

$$
\Theta(x ; r, \alpha)=\left(r^{2} x^{3}+x \alpha(1+2 r)-(2-\alpha) \alpha^{2}-r x^{2}\left(1+r(2-\alpha)+\alpha^{2}\right)\right)
$$

and

$$
\Phi(x ; r, \alpha)=\left(r x^{3}+x \alpha(1+2 r)-(2-\alpha) \alpha^{2}-x^{2}\left(r+2 \alpha+(r-1) \alpha^{2}\right)\right)
$$

The result is established by verifying that $\Theta(x ; r, \alpha)>0$ and $\Phi(x ; r, \alpha)>0$ for all feasible $x, r$ and $\alpha$.

We will show the existence of a value $r^{\prime}>1$ for which $d u^{a}(r x) / d x \gtreqless 0$ for $r \lesseqgtr r^{\prime}$. To do so, first observe that

$$
\begin{aligned}
\frac{d u^{a}(r x)}{d x} & =\frac{d u^{a}(x, r x)}{d x}+r \frac{d u^{a}(x, r x)}{d x} \\
& =\frac{r(1-\alpha)^{2} \alpha^{2}(x(1-x(1-r)) r-\alpha)\left(\frac{r(r x-1)}{r x-\alpha}\right)^{\alpha-1}\left(\frac{x(1-\alpha)}{x-\alpha}\right)^{-\alpha}}{(x-\alpha)^{2}(r x-\alpha)^{2}}
\end{aligned}
$$

We can see by inspection that $d u^{a}(r x) / d x$ is monotonically decreasing in $r$. Now if we fix $r=1$ we find that

$$
\frac{d u^{a}(r x)}{d x}=\frac{(1-\alpha)^{2} \alpha^{2}\left(x^{2}+\alpha-2 x \alpha\right)\left(\frac{x(1-\alpha)}{x-\alpha}\right)\left(\frac{(x-1) \alpha}{x-\alpha}\right)^{\alpha-1-\alpha}}{(x-\alpha)^{3}}>0
$$


So there must exist a value $r^{\prime}>1$ for which a doubling of $x$ has no effect on $d u^{a}(x, r x)$.

\section{References}

[1] Amir, R. and F. Bloch (forthcoming); "Comparative Statics in Strategic Market Games." To appear in Games and Economic Behavior.

[2] Amir, R. and V. Lambson (2000); "On the Effects of Entry in Cournot Markets." Review of Economic Studies, 67: 235-254

[3] Bagwell, K. and R. Staiger (2002); The Economics of the World Trading System, MIT Press, Cambridge, Massachusetts.

[4] Dixit, A. (1987); "Strategic Aspects of Trade Policy." Chapter 9 in Bewley, T. F. Advances in Economic Theory; Fifth World Congress, Cambridge University Press, Cambridge.

[5] Dixit, A. and V. Norman (1980); Theory of International Trade, Cambridge University Press, Cambridge, UK.

[6] Hamilton, B. and J. Whalley (1983); "Optimal Tariff Calculations in Alternative Trade Models and Possible Implications for Current World Trading Arrangements." Journal of International Economics, 15: 323-348.

[7] Jawara, F. and A. Kwa (2003); Behind the Scenes at the WTO: The Real World of International Trade Negotiations; The Lessons of Cancun. Zed Books, London, New York.

[8] Johnson, H. G. (1953-54); "Optimum Tariffs and Retaliation." Review of Economic Studies, 21: 142-153.

[9] Gorman, W. M. (1958); "Tariffs, Retaliation and the Elasticity of Demand for Imports." Review of Economic Studies, 25: 133-162.

[10] Helpman, E. and P. Krugman (1985); Market Structure and Foreign Trade, MIT Press, Cambridge, Massachusetts. 
[11] Kennan, J. and R. Riezman (1988); "Do Big Countries Win Tariff Wars?" International Economic Review, 29: 81-85

[12] Otani, Y. (1980); "Strategic Equilibrium of Tariffs and General Equilibrium." Econometrica 48: 643-662.

[13] Staiger, R., (1995). "International rules and institutions for trade policy." In: Grossman, G., Rogoff, K., (Eds), Handbook of International Economics, Volume III, North Holland.

[14] Syropoulos, C., (2002); "Optimum Tariffs and Retaliation Revisited: How Country Size Matters. Review of Economic Studies, 69: 707-727.

[15] Topkis, D. (1998) Supermodularity and Complementarity, Princeton University Press, Princeton, New Jersey.

[16] Whalley, J. (1985); Trade Liberalization among Major World Trading Areas, MIT Press, Cambridge, Mass. 